\title{
A health education programme to enhance the knowledge and communication skills of health care workers who serve people living with HIV / AIDS on HAART in Namibia
}

\author{
Mwakanyadzeni Abigail Chipare $^{1 *}$, Agnes van Dyk ${ }^{2}$, Hans Justus Amukugo ${ }^{3}$ \\ ${ }^{1}$ Public Health, Social, Gender issues and Substance Rehabilitation Advisor/Consultant PhD (2014) \\ Health Sciences School of Nursing and Public Health, University of Namibia (UNAM) \\ ${ }^{2}$ Director School of Nursing PhD Nursing (1967) Health Sciences and School of Nursing, University of Namibia (UNAM) \\ 3 School of Nursing and Public Health, University of Namibia (UNAM) \\ *Corresponding author E-mail: machipare@africaonline.com.na
}

\begin{abstract}
This paper aims at describing the findings of a health education programme that enhances the knowledge and communication skills of health-care workers who serve people living with HIV / AIDS on HAART in Namibia. Namibian health-care workers are unable to provide quality health care services to people who are living with HIV / AIDS (PLWHA) when they do not have the necessary knowledge, as well as adequate interpersonal communication and counselling skills. In a health care facility system, all patients either come from the community, or are referred from the wards or other departments by health-care workers. The health care worker as a sender conveys information (messages), and a patient (receiver) is expected to comprehend these messages and to respond by giving feedback to the sender who, in turn, provides feedback until the communication process is completed. The process should take place in a conducive environment without any interference, such as noise, to allow the swift completion of the communication process. The messages that both parties convey should be clear, accurate, coherent, and concise. This article covered the following: background, methods, ethical measures, results (participants' responses) conclusions and recommendations.
\end{abstract}

Keywords: Communication Skills; Health Educational Programme; HIV/AIDS ; Health Care Workers; Knowledge.

\section{Introduction}

CHS is a faith-based organisation and the second largest health service provider in Namibia, which operates in conjunction with the objective of the Namibian Government to address issues that are related to alcohol abuse and HIV / AIDS. Furthermore, the CHS has four district hospitals and 17 health care facilities throughout the country where it prioritises the HIV / AIDS programme in a catchment area with a population of 300000 . The CHS HIV / AIDS programme, furthermore, comprises about 800 health-care workers of whom $10 \%$ work directly with HAART patients. The programme is funded by the President's Emergency Plan for AIDS Relief (PEPFAR), under the auspices of USAID Namibia through their capacity project (Intra Health). In addition, it provides integrated services; such as the prevention of motherto-child transmission (PMTCT), antiretroviral therapy (ART), and voluntary counselling and testing (VCT).

The four CHS district hospitals in three regions care for a total of 20429 enrolled HIV-positive patients. The Kavango Region has two hospitals, the Andara Hospital with 3115 patients and the Nyangana Hospital with three 059 patients. The Oshikuku Hospital in the Omusati Region has 12100 patients, and the Rehoboth Hospital in the Hardap Region has $2155 \mathrm{HIV}$-positive patients in care. There are 13191 patients on HAART (CHS, 2011). It is well documented that HIV / AID is predominantly a sexually transmitted disease. Namibia has a generalised HIV epidemic where it is primarily transmitted by heterosexual activities. The increased prevalence rate among pregnant women was $18.8 \%$ in 2010 when compared with a 13 non-statistically difference of $17.8 \%$ in 2008 . Equally, behavioural and contextual issues are identified as driving contributing factors to HIV infection. Among the seven drivers of the epidemic, multiple concurrent sexual partners and alcohol abuse are regarded as the main causes of the rapid spread of the virus among young people (MoHSS, 2009). In 2006, $16 \%$ of men and 3 per cent of women of a sexually active age reported having more than one partner during a period of one year (MoHSS, 2008).

\section{Methods}

The researcher adopted a qualitative research methodology according to an explorative, descriptive, and contextual design. That was achieved through fieldwork in the context of the Catholic Health Services (CHS) district hospitals in Namibia. Participants were health care workers (nurses and community counsellors) and people living with HIV / AIDS on HAART.

\section{Purposive sampling}

The purposive sampling was conducted by including all four of the main CHS district hospitals; namely the Andara, Nyangana, Oshikuku, and Rehoboth Hospitals. A purposive sample technique 
was selected for the purpose of the study to determine the sample of the two groups of participants. These two groups were healthcare workers (nurses and community counsellors) who served people living with HIV / AIDS on HAART and people living with HIV / AIDS on HAART.

Group 1 criteria

All the health care workers had to be nurses and community counsellors who provided care to PLWHA on HAART and who were:

- Working for the Catholic Health Services at one of the four main health care facilities in Andara, Nyangana, Oshikuku, and Rehoboth;

- providing direct health care services to people living with HIV / AIDS on HAART; and

- Employed at a Catholic Health Services health care facility for at least one year.

- Group 2 criteria

- The PLWHA on HAART had to meet the criteria of:

- Being between the ages of 15 and 49 years (legal age for consenting to interviews), who were on HAART for a period of at least one year; and

- Visiting the health care facility on the day that the interviews were conducted.

\subsection{Data gathering}

Focus group discussions and in-depth interviews were conducted until data saturation occurred. The research questioned what factors deterred health care workers to effectively communicate with PLWHA on HAART and what type of interpersonal communication skills, counselling skills, and HIV / AIDS knowledge did health care workers have. The research question for people living with HIV/AIDS on HAART interrogated the type of health information they obtained from health care workers that improved the knowledge about their health? A voice recorder was utilised to capture information during all group discussions and interviews; data was transcribed verbatim.

\subsection{Data analysis}

Data analysis was guided by Tesch (1968) eight steps in Krueger and Casey (2009), Leech and Onwuegbuzie (2007). The researcher and the fieldworker did data coding while ensuring trustworthiness validation Shenton (2012), utilised data credibility, transferability, dependability, and confirmability.

\subsection{Ethical measures}

Ethical measures were observed throughout the study by observing the guidelines of Melville, et al. (2012) and De Vos (2009). Permission to conduct the study was sought and obtained from the University of Namibia Post Graduate Committee. In addition, the written proposal was reviewed by the committee to ensure that it conformed to the ethical standards of scientific research. Written permission to interview patients on HAART and to conduct focus group discussions at Catholic Health Service facilities was requested from the director of the Catholic Health Services. The ethical research included the protection of the human rights, literature, and experiences of health care workers and HAART patients.

\section{Results}

The results were achieved by analysing the three main themes and seven sub-themes of the study. These main themes are discussed in this article and include references to the sub-themes and quotations the participants (health care workers and people living with HIV/AIDS on HAART).

It was evident that health care workers who served people living with HIV / AIDS on HAART inadequate knowledge and communication skills. They had no guidelines that directed and encouraged them to effectively communicate with their patients. On the other hand, people living with HIV / AIDS on HAART did not receive the relevant health information from health care works that they needed to improve their knowledge about their health. These references support the literature control of this research project. The themes and sub-themes are presented in Table 1attached on this article.

Table 1: Main Themes and Sub-Themes

\begin{tabular}{|c|c|}
\hline Main theme 1 & Sub-themes \\
\hline $\begin{array}{l}\text { Health care workers experience } \\
\text { a lack of sufficient communica- } \\
\text { tion skills to address concerns of } \\
\text { PLWHA on HAART }\end{array}$ & $\begin{array}{l}\text { - Lack of experience in inter- } \\
\text { personal communication and } \\
\text { counselling skills } \\
\text { Lack IEC materials for dis- } \\
\text { seminating health information } \\
\text { to HAART patients }\end{array}$ \\
\hline Main theme 2 & $\begin{array}{l}\text { Sub-themes } \\
\text { - Lack of support in developing } \\
\text { knowledge through in-service } \\
\text { training to manage HIV / } \\
\text { AIDS }\end{array}$ \\
\hline $\begin{array}{l}\text { Health care workers experience } \\
\text { lack of exposure to HIV / AIDS } \\
\text { management }\end{array}$ & $\begin{array}{l}\text { - Lack of guidelines that clearly } \\
\text { assist HCWs to engage in the } \\
\text { management of PLWHA on } \\
\text { HAART }\end{array}$ \\
\hline & $\begin{array}{l}\text { - HCWs experience lack of } \\
\text { supervision from their superi- } \\
\text { ors to be able to manage HIV } \\
\text { / AIDS }\end{array}$ \\
\hline Main theme 3 & $\begin{array}{l}\text { Sub-Themes } \\
\text { Participants (HAART patients) } \\
\text { experienced a lack of information } \\
\text { in relation to: }\end{array}$ \\
\hline $\begin{array}{l}\text { PLWHA on HAART (patients) } \\
\text { experience insufficient infor- } \\
\text { mation about aspects of HIV / } \\
\text { AIDS that is essential to their } \\
\text { health }\end{array}$ & $\begin{array}{l}\text { - } \text { The prevention of HIV } \\
\text { - } \text { Adherence to treatment of } \\
\text { - BIV } \\
\text { - } \text { Blood results } \\
\text { - Alcohol abuse } \\
\text { - Nutrition } \\
\text { Participants (HAART patients) } \\
\text { indicated the need to be empow- } \\
\text { ered and enabled to manage dis- } \\
\text { closure, stigmatisation, and dis- } \\
\text { crimination }\end{array}$ \\
\hline
\end{tabular}

\section{Discussion and participants' responses}

Main theme 1: Health care workers experience a lack of sufficient communication skills to address concerns of PLWHA ON HAART

Communication is an act of transferring information from one person / place to another (Oxford dictionary, 2013). According to Webster (2012), communication is perceived as an act or process of transmitting information in the context of ideas, attitudes, emotions, or objective behaviour. As a process, communication comprises a sender and receiver(s) who are conveying information by using communication channels.

Adler, Procter and Towne (2011) describe communication as a process between at least two people when one person conveys messages or information to another. Moreover, these messages are mentally created in a form of images that a person desires to communicate to another. Messages / information can include ideas, thoughts, pictures, and emotions. Transferring such an image to another person, the sender must first transpose or translate the images into symbols that receivers can understand. Symbols often are words but can also be pictures, sounds, or sense information, e.g. touch or smell. Only through symbols can the mental images of a sender have meaning to other people. The process of translating images into symbols is called encoding and decoding. Review illustrations in Figure 1 below: 


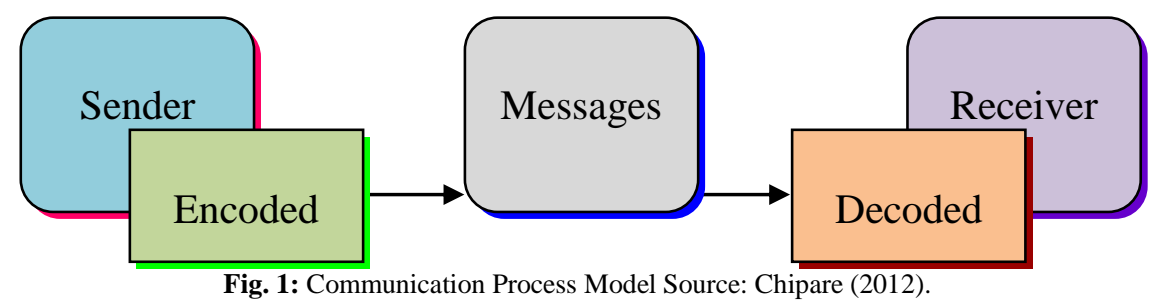

The encoded messages can be transmitted to the receiver in various ways. Spoken / verbal communication includes face-to-face conversations and communication by means of a telephone, radio, television, and mass media. Non-verbal communication involves body language, gestures, dress code, actions, and even our scent. Written communication takes place by means of letters; email, books; magazines; the Internet; other mass media; and visualisation like graphs, charts, maps, and logos. However, in order for one to encode messages / information accurately for the receiver, one needs to have communication skills. According to the definition in the Lexicon dictionary (2013), communication skills are the abilities of understanding language, communicating it expressively, and interpersonal communication skills. Therefore, in order for a health care worker to provide quality health care services, it is essential to communicate properly with patients / clients. To this end, a sender (health care worker) needs to have communication skills. In this study, it was found that health care workers experienced a lack of communication skills that prevented them from effectively communicating health information to PLWHA on HAART.

According to Meliones, Alton, Mericle, Ballard, Cesari, Frush, and Mistry (2008), developing communication skills require health-care workers to have the ability of communicating information accurately, clearly and as intended, and improving quality care. Furthermore, health-care workers need to have the ability to speak appropriately with a wide variety of patients / clients while utilising appropriate non-verbal communication; for instance, the way they attend to their clients, maintain good eye contact that demonstrates a variety of vocabulary, listen effectively, present ideas appropriately, write clearly and concisely, and work in groups.

In other words, effective communication (EC) is vital to health care workers and their patients. Therefore, EC is more than exchanging information but also includes understanding the emotions behind that information. It can improve relationships at home, work, and in social situations by deepening one's connections to other people by means of effective teamwork, decisionmaking, and problem solving. It is perfectly supported by interpersonal skills (in counselling) and non-verbal communication (body language) that include various communication skills, such as attentive listening (ability to manage one's stress, and capacity to recognise and understand one's own emotions and the emotions of other people) (Robinson, Segal \& Segal, 2011).

In health systems, communication is regarded as essential to health providers and patients, particularly the ones with chronic diseases such as diabetes, and HIV / AIDS. Patients expect of health care workers to provide them with information each time that they are seeking health care services. Some studies indicate that patients trust information that is provided by health care workers more than any other sources of information. This is recorded in a study about information preferences (Robinson, et al., 2011).

However, the challenges only emerge when that information is not being communicated effectively. With the emergence of technologies, communication has improved in health systems; for instance Namibia, in partnership with the US government, has utilised Electronic Patients Management Systems (ePMS) for investigating the risks of anaemia associated with Zidovudine (AZT), the first line antiretroviral drug that is part of HAART (Wily, 2011). This coincides with the time when health care workers in countries of Sub-Saharan Africa are facing challenges during imparting health information to patients that prevents the crippling effects of HIV / AIDS, intervention efforts, and slowing down the pace of distributing antiretroviral (ARVs) treatment (UNAIDS Global AIDS Epidemic Update, 2009).

Insufficient communication by health care workers consequently disadvantages patient with detrimental errors in care and treatment (UNAIDS Global AIDS Epidemic Update, 2009). Health care workers need to have abilities to communicate effectively in order to provide information to HAART patients about their health needs by including information about prevention, adherence, disclosure, blood results, nutrition, alcohol abuse, sexual relationships, and stigmatisation challenges they face every day.

Sub-theme: Lack of experience in interpersonal communication and counselling skills

Interpersonal communication skills are subconscious skills that develop throughout one's lifetime. These skills can be called life skills, social skills, soft skills, peoples' skills, or communication skills that encompass various techniques (Robinson, et al., 2011). Counselling is an interpersonal, dynamic communication process between a client and a trained counsellor that is bound by a code of ethics and practice to resolve personal, social, or psychological problems and difficulties. Counselling requires empathy, genuineness, absence of any moral or personal judgment, and the respect necessary to assist the client to explore, discover, and clarify ways of dealing with a concern (UNAIDS Report on Global AIDS Epidemic 2010). Both interpersonal and counselling skills are used every day in communicating, interacting, or in problem solving with other people, either individually or in groups. Interpersonal and counselling skills consist of:

Verbal: Effective verbal or spoken communication depends on a number of factors; such as listening skills and clarification by using techniques like openness, reinforcement, active listening, empathising, creating congruence, probing, reflecting, clarifying, and summarising (Robinson, et al., 2011).

Non-verbal communication: It refers to implicit messages, whether intentional or not, that are expressed through non-verbal behaviour. Non-verbal communication utilises various gestures; including facial expressions, tone and pitch of voice, and space (physical distance between the communicator and receiver); to convey messages / information from one person to another. These are gestures that allow people to understand the information put across to them by reinforcing or modifying what is said, for instance, the nodding of the head reinforces relationships between two people and it gives appropriate feedback and regulates the communication flow (Robinson, et al., 2011).

Listening skills: It is the ability to accurately receive messages / information during the communication process; it is the key to all effective communication (Robinson, et al., 2011).

Moreover, proficiency in both interpersonal and counselling skills is essential for conveying information from the sender to the receiver, particularly professionals who deal with patients and / or clients from different walks of life. The study outcomes indicated that health-care workers showed a lack of interpersonal and counselling skills when addressing different HIV / AIDS aspects of PLWHA on HAART. That was evident in the following statement from a health care worker: "Some of us don't even know where to start in tackling AIDS issues, during our professional training, we didn't include AIDS counselling". 
Health-care workers from one hospital further argued that providing health information to patients was complicated and that there were no HIV / AIDS experts in that particular area. In addition, the same concerns were shared by their colleagues at other hospitals who experienced difficulties in communicating with patients due to cultural factors that made it difficult for them to talk about sexual issues with the opposite sex or elderly people because of the misconceptions attached to the disease: "It is too difficult for us to communicate with patients yet they are entangled into their cultural and religious customs."

The same perceptions are identified in other studies where healthcare workers who work with a diverse population perceive patients' culture as a barrier to care, since they struggle to communicate with patients due to cultural barriers (Modo, Modo and Enang, 2011). With regard to interpersonal and counselling skills based on field notes taken throughout discussions with participants, this study draws attention to the fact that majority of participants, for instance:

- Male health care workers were not comfortable to address female patients on sexual issues as evident in the following quotation: "We are uncomfortable talking to women about sex issues".

- Younger health care workers found it difficult to address sexual issues with elderly persons. According to them: "Culturally, it was unacceptable for younger people to address adults".

- Health care workers were also uncomfortable with communicating or counselling teenagers who were on treatment because: "It was difficulties [sic] of communicating to young people about treatment due to their understandable [sic] level". In addition, in the case of death of a patient, for instance, healthcare workers indicated that: "We don't know how to break bad news to the family of the deceased and also providing bereavement counselling".

The researcher also noted that health care workers of antenatal PMTCT women experienced a lack of interpersonal and counselling skills because: "We don't have abilities to express ourselves when it comes to talking to expectant mothers".

Similarly, health care workers at two of the hospitals, who were pessimistic about providing counselling, experienced that in their working environment there were no private counselling rooms, limited resources and / or time allocated for counselling sessions, and most patients were hungry pregnant women with babies who travelled for long distances. "How can you expect us to briefly talk to patients who are hungry about their private issues in a public arena?" To further elaborate, those two hospitals were situated near the borders where most of their patients crossed the boarders from neighbouring countries; such as Angola, Botswana, and Zambia to seek health care services.

Effective communication was perceived as a burden to health care workers who struggled to cope with an influx of patients who were crossing the boarders and causing hospitals to be congested to their maximum capacity and the unavailability of supplementary food to feed pregnant mothers and children who travelled long distances.

"Our hospitals are always full to the capacity and there is not time to provide counselling to these patients because they will be exhausted, hungry and not pay attention to whatever information conveyed to them, all they thought about was to get their tablets and endure long distance back home since it was far".

Similar reactions are shared in UNAIDS Progress Reports (2012) that countries in Sub-Saharan Africa are still facing challenges in providing quality health care services to PLWHA due to inadequate communication skills, support structures, resources, and infrastructure. Furthermore, it is noted that the notion of excellent communication skills are associated with the delivery of high quality care. These views are confirmed by Robinson, et al. (2011) about the benefits of communication skills that assist clinicians and patients - in relation to health information - with the purpose of exchanging and promoting diagnostic accuracy, patients' knowledge, understanding, health outcomes, clinician-patient satisfaction, adherence to a treatment plan, patients' trust in clinicians, and reducing medical errors.

In conclusion, this Sub-theme gives an account of health care workers who reflect with mixed feelings about their abilities to communicate effectively with their patients. Health care workers exhibit these feelings when faced with challenges of communicating about sexual issues with opposite sex patients, addressing the same issues with elderly people, providing information to teenagers, bereavement counselling, and talking to expectant mothers.

Sub-theme: Lack of IEC materials for disseminating health information to HAART patients

Information education communication (IEC) refers to tools used to transfer knowledge to a targeted audience with the aim of assisting with the promotion of positive change (Edewor, 2010) The types of IEC materials are, e.g. graphic and audio-visual resources that include brochures, posters, display boards, bill boards, DVDs, slides, flip charts, flip cards, and counseling cards. It also includes mass media like radio, television, movies, newspapers, and magazines. IEC materials are categorised as either printable, or electronic. Printable resources include posters, brochures, flip charts, newspapers, and magazines while electronic materials include radio spots, television spots, and documentary movies. Health information should benefit PLWHA in the way it is presented to them. It should be informative, localised, simple, accessible, and easy to follow.

In this study, IEC materials are regarded as additional health information that is provided to HAART patients and members of the public (reachable and hard to reach) that promote health and raise awareness by utilising health communication strategies.

It was found that all four district hospitals in Namibia experienced an insufficient supply of IEC materials for disseminating health information to HAART patients. That was evident in the following statements:

"We don't have any designed tools for giving health information". "We give patients health information through watching videos, and not sure whether it covers the patients' needs".

While examining the nature of the phenomenon, the researcher found that the majority of health care workers were lacking the standardised tools and IEC materials that were relevant to PLWHA, particularly those patients on treatment. They expressed that:

"There were insufficient IEC materials in most of the hospitals during..."

According to UNAIDS Global Progress Report (2012) the shortcomings were identified in Sub-Saharan African countries that face insufficient resources and the development and distribution of IEC materials for PLWHA, particularly those patients who are residing in remote areas. Similar experiences are acknowledged in a study on nutrition done in Ethiopia, where IEC / BCC materials are in short supply while the bulk of the materials are of an inadequate quality. The same perspectives are held in Ghana where IEC messages for PLWHA are perceived as either gender-biased, or insensitive and stereotypical.

This study found that more than half of the health care workers took personal initiative by using the Internet as a source of information:

"Sometimes, I search from the Internet, most health information that I give to my patients".

This is similar to the perceptions illustrated by Coiera (2013) on telemedicine technologies by pointing out that Internet technologies were conveniently utilised for health care services delivery in developed countries. This is in contrast with other studies about Internet technologies that indicate information of such a nature is inconsistent and unreliable.

In this study, it was found that all district hospitals were utilising television as a mode of disseminating information. Participants indicated that:

"HAART patients are entertained by watching television while waiting on [sic] the long queues." 
In contrast with how the patients perceived television, some health care workers reported:

"[The] majority [of] patients perceived television consequently as more entertaining than educative since they preferred watching African movies".

They further uttered that "most recorded movies were more entertaining than educative, such as African movies."

The majority of health care workers at their facilities were utilising expert patients (EPs) and support groups as sources of information:

"Due to lack of time and resources, we always refer our patient to EPs where they received health education and counseling although we are all aware that they had no formal training."

At the time of the study, health-care workers relied on EPs who was attached to the hospital for assisting them in paediatric departments, and at antenatal clinics where their responsibilities were to retrieve and fill in patients' files. Some studies indicate that information should be perceived as important to PLWHA on HAART because it assists them with making decisions about treatment and specific support they need. Therefore, information is valuable and an important part of coping with illness. This includes communicative and cognitive activities like seeking, avoiding, providing, appraising, and interpretive information (Robinson, et al., 2013). Similar views are shared by Edewor (2010) who states that insufficient information can compromise the success of treatment and other HIV prevention interventions. Therefore, patients need to be provided with relevant, accurate, and timely information that addresses their health needs.

This study further found that health care workers expressed their concerns about printed information:

"Specifically patients come to the facilities to collect pamphlet, or posters and used them to make fire at their homes because they did not understand and read, since most of messages were written in [the] English language not in their vernacular languages".

In the context of Sub-Saharan Africa, IEC strategies are perceived as appropriate strategies for raising awareness and reducing HIV / AIDS in countries like Kenya, Tanzania, South Africa, Botswana, and Uganda (UNAIDS Progress Report, 2012).

In conclusion, participants expressed their concern about the shortage of IEC materials and tools for disseminating information to PLWHA on HAART at their facilities. Most pamphlets or posters were written in English which made it difficult for patients to read and understand. That led to patients using the posters for starting a fire at their homes. Insufficient IEC materials at all facilities resulted in health care workers rather using the Internet as a source of information. Television was used to entertain patients, not necessarily educating them, while they were waiting in long queues. Health care workers utilised expert patients' services for providing counselling and education to PLWHA on HAART due to a lack of time, resources, and infrastructure.

Main theme 2: Health care workers experience a lack of exposure to HIV / AIDS management

Exposure refers to advances of knowledge about the mechanisms and dynamics of an event, either causing or preventing adverse health outcomes (Lexicon dictionary, 2013). In this study, exposure indicates health care workers' ability to manage knowledge while dealing with HIV / AIDS aspects that lead to quality health care services to PLWHAs. Therefore, in order for health care workers to master the management of HIV / AIDS knowledge, they need to be guided by the existing collection of policies and frameworks that support their initiatives in interpersonal communication skills for exhibiting their performance and attitudes towards their patients. Moreover, health care workers need to have knowledge about the disease itself, its progression, transmission, prevention, treatment, care, and support.

Health care workers are experiencing a lack of exposure to HIV / AIDS management. This statement is supported by the following quotations:

"Information about the epidemic is evolving and we want to be updated with new information about universal intervention strategies, care, and support for PLWHA".
"We want more workshops to take place in our facilities HIV / AIDS management".

In addition, the study findings indicated that health care workers were not comfortable with operational policies because they lacked a clear definition of the scope of work and allocation of tasks that particularly addressed the health needs of PLWHA on HAART. This perception was illustrated:

"In their facilities, there were no structures or uniformity orderly ways of operating day to day activities".

In the development of communication skills guidelines, communication theories are emphasised that assist in setting frameworks to guide health care workers during planning of and setting goals for their daily activities (Wouda \& Van de Wiel, 2012). Examining the nature of the matter, the majority of participants indicated:

"Health care workers expressed that they had limited knowledge on the epidemic despite the evolving information".

The attention of the researcher was also drawn to:

"Health care workers indicated that the work that they do was delegated to them by the supervisors; there was no planning or any administration done".

Health care workers lose direction in providing quality care to patients because they have no knowledge about the organisation and analysis of information to make it understandable and applicable to problem solving or decision making. These skills are necessary for capturing knowledge to ensure the preparedness of public health services. Managing information is more effective and collaborative in a virtual environment, since it improves effectiveness in the face of dwindling resources (Malmberg, Harmon, Nauer, \& Richard, (2012).

In conclusion, health care workers express their concerns with regard to insufficient knowledge in HIV / AIDS management, since it affects their daily operations at the health facilities. According to them, they experience a lack of uniformity when planning day-to-day activities. Most of their work is delegated to them by supervisors. There are no operational policies or curriculums to direct them.

Sub-theme: Lack of support in developing knowledge through inservice training to manage HIV / AIDS

Support means contributing or assuring success (Oxford dictionary, 2013). In this study, support means empowering health care workers with relevant skills and tools for enabling them to deliver quality health care services that improve the lives of HAART patients. It was found that participants experienced a lack of support in developing knowledge through in-service training to manage HIV / AIDS. This was evident in the response of participants:

"At our hospitals, there are no structured curriculums or manuals that can guide us health information communication thus why we rely on own initiatives".

The majority of the respondents shared this opinion:

"Health care workers were educating themselves through Internet technology, although struggling to pay for internet services at the cafes".

In examining the nature of the phenomenon, it emerged that Internet access was a major challenge at all hospitals, since they were trying to limit some costs of installing Internet access in every office; the only connections were in the managers' offices.

A similar view is shared by Coiera (2013) that utilising the Internet and other technologies have evolved, particularly in most developed countries where the Internet improved communication and care of patients. Health providers communicate with their colleagues much easier and faster while sharing ideas on patients, diagnosing, accessing patients' files, retrieving new health information, and accessing technologies.

The majority of health care workers at all four CHS hospitals expressed their concerns about training:

"Most of the trainings provided by the Ministry of Health targeted our managers only, but now the problem was they don't even come and share or give use in-house training".

"We always hear about these on-going trainings but we have not reached us here in rural areas".

It was found that: 
"More than half [of the] participants work in district hospitals situated in remote areas of different Namibian regions; namely north, northeast and south, and not feasible for all HCWs to leave patients and to attend training".

Findings of other studies state that workshops and in-service training have an effect on communication skills, particularly of health care workers who are working directly with patients. Similar views are shared in a paper about patient education and counselling which indicates that training boosts self-perceptions of confidence and competence in caring for the patients (Malmberg, et al., 2012).

A further notion of inadequate training was argued by a health care worker from one of the hospitals:

"I only heard that NGOs are the ones giving HIV / AIDS training but to attend required some recommendations from your supervisor... In most cases, the manager attends alone".

However, the study found that:

"Training health care workers at the facility level were through NGOs perceived as the most convenient strategies in most hospitals because it was cheaper and no travelling involved and accommodating participants".

Most organisations that were working with PLWHAs had offices at the facilities. The majority of participants argued:

"Their dilemma was for them to attend these training required approval letters from supervisors".

Despite these shortcomings, some other studies emphasise that employers assist health care workers to acquire appropriate training at all levels of responsibilities in order to increase an understanding of HIV / AIDS and to help reduce negative and discriminatory attitudes toward colleagues and patients who are living with HIV / AIDS. The World Health Organization Report with the title "Towards universal access: Scaling up priority HIV/AIDS" (2009) states that such training needs to include the etiology of the disease and provide a platform for continuing learning, improving interpersonal skills, understanding the impact of HIV / AIDS and the burden of stigmatisation, as well as providing the tools to communicate with patients.

In conclusion, health care workers express their concerns about the lack of support for in-service training at their facilities that paralyses their efficiency and effectiveness in providing quality care to PLWHA on HAART. They add that there is no structured curriculum or manuals that could guide them in health information communication. Therefore, they have to resort to the Internet for guidance.

Sub-theme: Lack of guidelines that clearly assist health care workers to engage in the management of PLWHA on HAART

A guideline refers to a principle or criterion that is guiding or directing action (Oxford dictionary, 2013). In this study, guidelines and frameworks describe operational directives (action plans) that guide health care workers in their day-to-day activities.

The study outcomes indicate that in Namibia there are no specific guidelines with regard to communication skills that clearly stipulate the roles of health care workers in HIV / AIDS management This is evident in the following statement:

"As far as I am concerned, here at our health facility, there are no guidelines that define our roles and how we can address PLWHA the needs".

The majority of participants from all four CHS hospitals uttered their discomfort about the content of HIV Counselling and Testing (HCT) guidelines which they said contained limited information about their responsibilities in HIV / AIDS management:

"HCT guidelines are not clear in how we can provide counselling to PLWHA on HAART. The content covers few issues in counselling not detailed health education".

In the context of Sub-Saharan Africa, a lack of urgency to develop guidelines that advance skills for health care workers who are caring and supporting HAART patients is a matter of concern. Consequently, the performance and work of health care workers are affected. A similar view is shared in other studies that state a lack of appropriate guidelines in most developing countries compromises quality health care services and performance of workers
(Wouda, et al., 2012). The same research report further emphasises the importance of empowering patients and physicians during frequent discussions to improve the effectiveness required for the development of guidelines to teach communication skills.

However, the findings indicate that:

"Health care workers need operational and programmatic guidelines that guide them in providing quality health care services, treatment, care, and support to PLWHA on HAART; particularly on these times where integration of HIV / AIDS health care services into primary health care, had took its drastic changes that affected the most health care departments with regards to staff rotation, task shifting and absenteeism of other HCWs due to illness".

These perceptions are illustrated in the WHO Report Global Summary Report with the title "Towards universal access: Scaling up priority HIV/AIDS" (2009) which indicates that guidelines are essential to health sectors, since they assist with defining and planning HIV programmes while linking them to the wider health policies, strategies and plans, as well as the wider multi-sectoral AIDS response. These guidelines need to emphasise the principles that focus on: The outcomes and maximising returns on investment; describing main components of a sectoral HIV plan, such as situation analysis, prioritisation, approach to service delivery, monitoring, and costing; as well as establishing a direct link between strategic, and operational planning and implementation.

In conclusion, this study notes that from the health care workers at all four CHS hospitals advocate for the development of a communication skills guideline that would guide and direct health care systems in developing frameworks that assist health care workers with planning and implementing relevant programmes that address the health needs of expanding PLWHA treatment, care, and support of health care services.

Sub-theme: Health care workers experience lack of supervision from the superiors to be able to manage HIV / AIDS

Supervision is a process of guiding, helping, training and encouraging staff to improve their performance in order to provide highquality health care services. Supervision is complex, especially in health care services, where there are different health care facilities, levels of care, types of care, services provided and ways to pay for those services where people still need such services and provide those services (Wouda, et al., 2012) Therefore, in order for health care workers to provide quality health care services to HAART patients, their performance needs to be guided and supported during their day-to-day activities. However, the study results illustrate that health care workers are experiencing a lack of supervision from their superiors that prevents them from managing HIV / AIDS. This is evident in the following statements of participants: "We don't have sense of direction due to poor supervision".

"We discovered that even supervisors have no clues on HIV / AIDS management".

"No one from the management team or from the national offices concerned about what we do".

It was found that the majority of participants at all four CHS hospitals expressed their discomfort with regard to poor supervision from their superiors at their facilities.

These perceptions were confirmed by another health care worker: "Disgruntled on the attitudes of supervisors referencing their behaviours as insensitive towards staff members, even if one had pressing personal issues found it difficult to approach supervisors".

The majority of health care workers from the four CHS hospitals disapproved of supervision methods and of being supervised:

"Supervisors always made excuses not to supervise them due to workload they encountered at the facilities and not paying any attention to us (health care workers) who working directly with PLWHA".

To elaborate further, the majority of health care workers agreed: "[At] their facilities, they had no open door policy where one can just walk in and be welcomed by the supervisor".

"Most of the time they complain that they did not want to be disturbed sticking out a 'Do not disturb' warning sign". 
Garrison in Wouda, et al., (2012) urges supervisors to abide by their obligation and responsibilities in supporting their members of staff and states that supervisors could help staff to acquire skills that are essential for completing any given tasks effectively (Wouda, et al., 2012). This could be made possible by improving communication, transferring knowledge / skills, in-service training, and building opportunities of targeted needs for particular members of staff in the context of day-to-day work (Pecora, Cherin, Bruce \& De Jesus Arguello, 2010).

In conclusion, health care workers experience a lack of supervision from their superiors which they perceive as affecting their performance and provision of high-quality care to PLWHA on HAART. Health care workers view supervisors as their mentors and expect them to guide, assist, train, and encourage them in their day-to-day activities.

Main theme 3: PLWHA on HAART experience insufficient information on HIV / AIDS aspects essential to their health Information refers to an abstract entity (Chmielecki, 2008). Various theorists define information as data, facts, intelligence, and advice. Information can be knowledge or wisdom. People acquire information through reading, studying, and practical experiences. Information can also be provided by telling, reading, or communicating facts that may be disorganised and unrelated. The concept of knowledge, however, is perceived as an organised body of information or as comprehension and understanding that are based on an acquired and organised body of facts. Furthermore, wisdom is viewed as knowledge of people, life, and conduct with facts thoroughly assimilated to produce sagacity, judgement, and insight (Oxford dictionary, 2013).

Information is essential to PLWHA and cannot be ignored (Edewor, 2010), particularly to those patients who are on treatment. Information is seen as an important part of coping with their condition. Therefore, HIV / AIDS service providers should have tenacity in prescribing types of information they assume is relevant to the needs of PLWHA, including medical information and information about social services. The same report further indicates that, the nature of information required by PLWHA should be based on their needs and can be categorised in different stages of the epidemic; such as the period of infection, initiating HAART, prevention, care, and support.

Ever since the age of the epidemic, information has been perceived as a critical requirement. Information is used for prevention of HIV, management of complications of the disease, and prolong ing of lives. Since PLWHAs are now leading productive, healthy lives and the morbidity and mortality rate has been reduced, the roles of information change, including information for the health care providers. Nowadays, information needs to focus on empowering PLWHAs in maintaining their new lifestyles. However, the challenges are whether the meaning of the information is being communicated accurately, clearly, and educationally as intended to improve the quality health of PLWHAs (Robinson, et al., 2011).

Subtheme: PLWHA ON HAART experience a lack of information The outcomes of the study identify that PLWHA on HAART experience a lack of information in relation to: The prevention of HIV, adherence to treatment of HIV, blood results, sexual relationships, alcohol abuse, and nutrition.

\subsection{HIV / AIDS prevention}

In this study, the concept of HIV prevention refers to activities or information that stops negative actions or behaviour of PLWHA while promoting positive behaviour. The current study findings add substantially to our understanding that PLWHA on HAART experience insufficient information about HIV prevention. Moreover, the participants (HAART patients) expressed their discomfort with insufficient information on HIV prevention that they were provided with by health care workers each time they visited the health care facilities. This was evidence in the following statements:
"My partners say they enjoy sexual intercourse without protection".

"I am discharging smelly fluid from my private part but still my partner still demand having sexual intercourse".

The majority of participants from the four CHS hospitals indicated:

"They had immense information on using condoms for protection but they didn't know how to convince their partners about the dangers of unprotected sex".

However, the study findings indicate that the health of the majority of PLWHA on HAART has improved ever since the ARVs intervention, therefore, their priorities have changed, since they now feel strong and physically fit and see no reason for not leading normal lives.

In examining the nature of the shortcomings:

"Participants argued that condom use was not an option since their health has improved".

Most participants reflected that the use of condoms was preventing them from conceiving while they were also chasing their partners away. Therefore, they preferred to use protection methods that were acceptable to their partners:

"Participants further demanded more information on how to prevent re-infection and prevention interventions, including counselling and specific health care services".

Similar views are acknowledged in UNAIDS Report on Global AIDS Epidemic (2010) which states that since the antiretroviral interventions, many opportunities have been missed in addressing prevention in terms of treatment, care, and multiple points of contact between health services and PLWHA. The consequences are confirmed in UNAIDS Global AIDS Epidemic Update (2009) which indicate that the main focus of HIV prevention in SADC regions is on rolling out of ARV treatment in the absence of prevention activities; this vacuum contributes to new HIV infections. Adherence to Treatment

The term adherence is a process of being dedicated to do something (Oxford dictionary, 2013). In this study, adherence describes a patient's commitment to carry out a prearranged plan of treatment, including food intake, in a sustainable fashion. The commitment of HAART patients to life saving treatment is determined by individual circumstances.

The study found that most of the participants were experiencing a lack of information on treatment and that was conveyed through the following statements:

"How can I take my tablets everyday with no food?"

"Health care workers always shout at me if I miss my tablets".

"Sometimes, I fail to go and get my tablets because the hospital is very far".

"I feel strong now; think of stopping taking these tablets".

The findings indicate that the majority of participants also explain their emotional rollercoaster while they are taking their ARVs:

"They further elaborated that in most occasions taking ARV drugs without eating food made them experience severe side effects; such as vomiting, diarrhoea dizziness, insomnia, and dementia".

According to the field notes, the majority of participants came from poverty stricken areas; most of them relied on harvesting crops to earn a living. For several years, they were experiencing persistent draught with the result that they neither had staple food, nor any other source of food. Furthermore, some participants complained about travelling long distances from their rural villages to health care facilities to collect ARVs. Sometimes, they also missed appointments due to the distance from the health facilities. In the interviews, most participants expressed their ignorance of information about the myths and misconceptions about HAART treatment.

This majority of participants raised the issues surrounding misconceptions about HAART treatment and a cure for AIDS by saying:

"Having sex with a virgin, animal, or use crocodile fat when having sex cures HIV".

However, it was found that: 
"More participants indicated that these misunderstandings were circulated by their social networks and media".

Despite these misunderstandings, AIDS has no cure. Having sexual intercourse with a virgin, although it was prevalent in SubSaharan Africa, is considered a crime and having sex with an uninfected virgin actually exposes that poor girl to HIV infection. Perpetrators are supposed to be incarcerated by the laws of the country, (UNAIDS Global AIDS Epidemic Update, 2009).

Furthermore, one of the participants witnessed a procession of men having sexual intercourse with an animal at their village in the northeast of the country where a cow gave birth to a humanlike animal.

Although sexual intercourse with animals was recorded in South Africa, Namibia, as well as in other countries, having sexual intercourse with animals is perceived as an act of cruelty. Furthermore, there is no documented evidence which suggests that sexual contact with an animal actually could cure AIDS (UNAIDS Global AIDS Epidemic Update, 2009).

"Participants specifically indicated that their religious beliefs [do] not permit them [to] keep on using ARVs drugs".

This perception illustrates that these frequent misconceptions about AID treatment result from simple ignorance and misunderstandings with regard to the knowledge on HIV infection, the etiology of AIDS, and how ARV treatment works. Contrary to various studies that indicate the factors associated with nonadherence originate from a lack of awareness about the treatment itself, public ignorance and the misunderstanding of the etiology of the epidemic (Baltazary, Akarro \& Mussa, 2011).

Blood Results

In this study, blood results refer to the feedback given to HAART patients by health care workers on information about their CD4 count and the levels of the viral load in their blood. It is often said, "Life is in the blood!" There are various reasons why it is important that HAART patients need to know more about the condition of their blood. Therefore, health care workers have an obligation to adequately empower HAART patients with information with regard to their blood in order for them to make the right decisions about their health (Edewor, 2010).

The majority of participants (PLWHA) were not given accurate information about their blood results. That was evident in the following statements:

"I told one of the health care workers that I wanted to have a baby, she told me to come for my blood to be tested, but did not tell the reasons why?"

"How can I stay health with this virus eating me up?"

"I was told that my blood was OK".

"The health care workers told me that there was CD4 count and viral load in my blood, what does it mean, or does it mean I about to die or what?"

"Do I have to start my medication right away?"

The findings of the study demonstrated that majority of participants were not knowledgeable of the medical terms that were used by health care workers. The most confusing terms, according to them, were normally used every time they were asking about their blood results. These terms included "CD4 count and viral load". In addition, it was found that the majority of participants complained a lot about the attitudes of health care workers with regard to feedback on their blood results.

After they had travelled for long distances, some participants were so disgruntled by the way they were treated by health care workers, who told them that their blood results were not in from the laboratory.

Some expressed their emotions, saying that their pregnancies were at an advanced stage but still they were told to wait for blood tests of their CD4 counts and viral loads. A participant from one of the hospitals was too emotional when she explained how badly she and her husband waited for her blood results and wanted to conceive and have a baby. Unfortunately, the husband died prematurely before the procedures were done.

Similar views where shared by one of the participants from another hospital who claimed that the last time he received his blood results was in 2004; he knew about his HIV status and was told that he was all right. That made the HIV positive patient to disappear from the system and by the time he visited the hospital, he was hospitalised with serious illness and was told that he experienced a CD4 count fall and his viral load was too high. He still did not understand what the information meant. He developed severe side effects because he was not on treatment for a long time.

The concepts of viral load (HIV-RNA) and CD4 count are perceived as the measure of the disease progression and survival as described by Akinsegum Akinbami (2012). The report further elaborates that this notion of CD4 count - although perceived as part of the immune system - is viewed as the strongest precursor of risking AIDS and death. This means that HIV over time destroys CD4 cells making the immune system weaker. Therefore, it is viewed as one of the determinants for measuring the strength and weakness of the immune system in the patients' bodies (Akinsegum Akinbami, 2012).

\subsection{Sexual relationships}

The term sexual relationship refers to a relationship involving sexual intimacy (Oxford dictionary, 2013). Sexual relationships can be influenced by every culture, sub-cultures, or differences in individual values. It includes a positive and respectful approach to sexuality and sexual relationships, as well as the possibility of having pleasurable and safe sexual experiences free of coercion, discrimination, and violence.

In this study, the sexual health of PLWHA refers to sexual relationships with respect to desires, concurrent sexual relationships, family planning, and childbirth. Due to ARV initiation, PLWHA are leading a healthy life and sexual perceptions of both men and women have changed; e.g. changes in numbers of partners, desire to start families, and desire to have babies (Degu, Yimer, Berhane $\&$ Melkamu, 2006). For PLWHA on HAART to live positively, they need to be provided with relevant information that addresses their health concerns without compromising their health. This information should not only focus on what they should be doing but also on what they should not be doing (Bell, Mtembu \& O'Sullivan, 2007).

The study findings demonstrate that PLWHA on HAART experience a lack of information about their sexual needs. This is evident in the following statements:

"Now, since I feel health [sic] my condition has improved, this is the right time for me to get married and have children".

"I missed my period, but I was taking some family planning tablets".

The study found that the majority of participants (HAART patient) expressed their concerns with regard to treatment they received from health care workers as displeasing each time they asked specific questions about family planning and / or childbirth. A variety of studies suggests that HIV positive women have the same rights as other women and also need access to HIV specific information and services (Gruskin, Ferguson, \& O'Malley, 2007).

The majority of HAART participants uttered similar concerns in relation to HIV specific information by saying:

"I can have as many sexual partners as I want".

"I am a driver and my work takes me away from home where my wife is, sometimes [I] engage in unprotected sex with different women".

"My customers demand unprotected sex at a high cost".

These perceptions illustrated that participants (PLWHA) wanted to know how they could disclose their HIV status to sexual partners without compromising their health. Some participants mentioned that:

"Sometimes using condoms makes them uncomfortable and time consuming, since they were long distance truck drivers".

In Namibia, the study done on the drivers and the HIV / AIDS epidemic under the auspices of the Ministry of Health and Social Services (MoHSS, 2009) states that multiple concurrent partnerships (MCPs) are perceived as one of the main drivers of HIV transmission in Namibia which makes all people who are prac- 
tising it vulnerable to contracting HIV. Moreover, the same report states that PLWHA on HAART experience inadequate education and / or relevant information about the dangers of MCPs to their health.

Some researchers suggest that there is a correlation between MCPs and HIV transmission among PLWHA on HAART that consequently is compromising prevention and treatment efforts, is preventing ARVs to decrease viral loads to undetectable levels in the short to medium run, is causing the durability of first line treatment to be average, i.e. less than five years, while the first line treatment is weakening, viral loads are fluctuating, and the infectivity of individuals on HAART is increasing (Mah \& MaughanBrown, 2009).

\subsection{Alcohol abuse}

The Centre for Disease Control and Prevention (CDC) (2013) defines alcohol abuse as the pattern of drinking that results in harm to one's health, interpersonal relationships, or the ability to work. The manifestations of alcohol abuse include failure to fulfil major responsibilities, such as driving or operating heavy machinery.

In this study, alcohol abuse describes the general implications of alcohol that are associated with the health of PLWHAs that contribute to the interruption of ARVs treatment. This causes nonadherence; susceptibility to communicable diseases, such as STIs, $\mathrm{TB}$, and re-infection that causes HIV stress and risk of the further spread of the virus; as well as exposure to certain types of behaviour, such as the prevalence of MCPs and its consequences. The outcomes of this study demonstrate that HAART patients on ARVs have insufficient information about the dangers of alcohol abuse:

"Taking ARVs requires a full stomach, so I drink alcohol with my ARVs".

"In our villages, alcohol is part of socialisation, so yes. I do drink alcohol".

"As long as I don't forget taking my ARVs, I do drink alcohol because it helps me to sleep in the night".

It was found that most participants strongly felt that there was nothing wrong with taking their ARVs with beer whereas some of them indicated that beer was one of their staple foods, especially home brew beer, since it had been part of their lives for a long time and they could remember that the elderly had normally used it for weaning babies:

"Participants further reluctantly find it difficult to just stop drinking alcohol".

"Other participants reiterated and said alcohol made them feel good about themselves and prevent insomnia problems. So, it was difficult for them to quit".

Studies done in Sub-Saharan Africa describe the implications of alcohol abuse among HAART patients as associated with various issues that result from the interference with ARVs treatment. These issues contribute to non-adherence, accelerating progression of the disease, increasing likelihood of having multiple concurrent partnerships and having unprotected sex, the effects of infectious diseases (STIs) on the immune system, diseases associated with neuropsychiatric disorders related to cardiovascular ailments, and the effects on internal organs such as the liver and the pancreas as described by Baliunas, Pandrea, Hendershot, Corrao in (Rehm, 2012).

Despite these shortcomings, dealing with alcohol abuse and HIV requires policymakers and implementers to address alcohol related interventions that are aimed at increasing safer behaviour, such as condom use in conjunction with other issues like partner reduction and mutual monogamy. This includes the development and provision of education and training programmes for PLWHAs and the community. Therefore, the IEC educational materials should be a discussion point among PLWHA on HAART and health care workers (Habtemariam, Tameru, Nganwa, Beyene, Ayanwale, Robnett, \& Wilson 2008).

\subsection{Nutrition}

Nutrition, nourishment, or aliment refers to the supply of food required by organisms and cells to stay alive. In this study, patients' nutrition refers to the food requirements of patients, including nutritional solutions delivered via an IV (intravenous) or IG (intra-gastric) tube (Lexicon, 2013).

It also refers to knowledge and means of getting the right amounts of good nutrients from local foods and in the right combination as a key to avoiding illness and many other chronic diseases.

The outcomes of the study demonstrate that PLWHA on HAART experience insufficient information about nutrition:

"I cannot afford the type of food that is recommended by health care workers."

"Every time when I mix my diet with milk, [it] makes me have a running stomach".

"These ARVs increase my appetite and I have no idea which type of foods can make my stomach full".

"I cannot afford fruits and vegetables that nurses always talk about".

In addition, the findings of the study indicated that the majority of participants displayed their ignorance with regard to the right diet for maintaining their health.

A similar view was shared:

"Other PLWHA[s] on HAART [are] grumbling due to lack of proper foods in their areas because of some persistent draught".

"Participants were confused on what they should or should not eat".

Participants further expressed their educational needs for maintaining their diet by eating their own local foods or for starting gardening projects to sustain themselves. The sustainability of a nutritious diet is emphasised in many research studies. This requires the integration of healthy eating programmes that need to include local food recipes because local food is cheap and affordable for local people (UNAIDS Global Report, 2012).

A similar view is expressed by the WHO Global Report Global Summary of AIDS epidemic (2009) that considers ART as an essential component of care for PLWHAs. However, nutritional interventions need to be incorporated into HIV treatment programmes. On the other hand, health care providers need to acquaint themselves with new knowledge about nutrition, counselling, and management of limited resources.

However, it was found that most participants came from poverty stricken areas of Namibia and they had neither formal jobs, nor any source of income. Therefore, they were struggling to make ends meet. Furthermore, some of the participants went out of their way and pleaded with the Namibian Government to declare HIV / AIDS as a disability so that they might earn a living through disability grants:

"[The] majority of participants further indicated their struggling in acquiring nutritional food".

Ashely and Lush (2007) show the same results in their findings about treatment literature for PLWHA and state that they are struggling to take their medication on an empty stomach because they could not afford three meals per day due to their lack of earning an income. The same concerns about the lack income among PLWHAs are acknowledged in Sub-Saharan Africa where socioeconomic and psychological factors are seen as contributing challenges among PLWHAs to non-adherence (UNAIDS Global Report, 2012).

In conclusion, the study draws attention to the needs of health information by PLWHA on HAART that would improve their knowledge about their health. According to the outcomes of the study, PLWHA on HAART experience inadequate information with regard to HIV prevention, adherence to ARVs, blood results, sexual health, alcohol, and nutrition.

Sub-theme: PLWHA on HAART indicated the need to be empowered to enable them to manage disclosure, stigmatisation, and discrimination

Empowerment is a process of enhancing the capacity of individuals or groups to make choices and to transform those choices into 
desired actions and outcomes (Lexicon dictionary, 2013). In order for HAART patients to make informed choices about their health they require to be empowered with appropriate and accurate information with regard to disclosure, stigma, and discrimination in their communities and workplaces. PLWHAs are reluctant to disclose their HIV positive status because they fear being stigmatised and discriminated against by partners, family members, colleagues, and the community in general (UNAIDS Global Report, 2012).

In this study, the findings demonstrate that PLWHAs on HAART are reluctant to disclose their HIV status because they are afraid of being stigmatised and discriminated against.

\subsection{HIV disclosure}

With regard to disclosure, the study found that PLWHAs on HAART expressed their need to be empowered to disclose their HIV status without compromising their relationships with people whom they loved:

"I am afraid to approach my partner about my HIV positive [status] because he will break up with me".

"I don't know how to tell my parents that I am HIV positive".

"My body weight is failing [sic] but people at [my] workplace are suspecting that I might be ill but I don't know how to break the news to them about my HIV positive status".

It was found that the majority of participants were single women who revealed that their reluctance to disclose resulted from fear of being victimised by their partners who might accuse them of infidelity and bringing the deadly disease into their relationship. Similar views are supported in a study done in Ethiopia on reasons for non-disclosure; respondents were afraid of being victimised or fearing separation / divorce or even accusations of infidelity (Deribe, Woldemichael, Wondafrash, Haile, \& Alemayehu, 2008) However, it contrasts with other participants who perceived disclosure as the right thing to do because it enabled partners to make mutual decisions in relation to treatment, sexual behaviour, reproductive choices, and access to further social support (Bradley, Remien \& Dolezal, 2008).

\subsection{Stigma and discrimination}

Stigma comprises two Greek words sigma $(\Sigma)$ and tau $(\mathrm{T})$ and has two meanings: (1) In Christianity, stigma refers to body marks that resemble the crucifixion of Jesus Christ, and (2) in a secular context, stigma is used to describe marks of disgrace, discredit, or infamy. In a social context, the term stigma is more frequently applied to social disgrace than to body signs or tattoos. It can be either internal or external. External stigma refers to actual experiences of discrimination. Internal stigma refers to imagined or perceived stigma (Ngozi, Mbonu, Nanne, De Vries, 2009). Discrimination is the actions or results of stigmatisation (Chirawu, 2009).

In this study, stigma and discrimination have three meanings: (1) Self-directed stigma, i.e. PLWHAs are being judged by others that results in self-hatred, shame, and isolation; (2) perceived stigma, i.e. the reality of being singled out, stigmatised, and discriminated against; and (3) enacted stigma that leads to active discrimination and negative behaviour towards PLWHAs (Chirawu, 2009).

Extensive studies were done on stigma and discrimination which concluded that stigma and discrimination were linked to disclosure and prevented PLWHAs from seeking treatment and access to quality health care services. After many decades with AIDS in our midst, PLWHAs are still victimised, burnt alive in some countries, or even killed because of their HIV positive status. This is a clear indication that society is not yet prepared to condone the epidemic (put a face to the disease).

In this study, it was found that PLWHA on HAART needed to be empowered to deal with HIV / AIDS related stigma and discrimination:

"Each time we visit [the] HAART Centre for ARVs re-fill, health care workers shout and call us names about our HIV status".
"I have no friends anymore, even my treatment supporter. She was victimised by the community because she befriending [sic] me".

"I prefer to be on my own, since I was told I was HIV positive". "When I told my employer that I was HIV positive, he / she changed my work shift".

It was found that the majority of participants in this study were stigmatised and being discriminated against in one way or another, since their status was known to a second or even a third person. According to them:

"The manifestation of stigma and discrimination comes only when they want to engage with the society or community they live in".

Stigma has negative connotations as seen by many, because it enhances secrecy and denial, which can be a catalyst for HIV transmission (Ngozi, et al., 2009).

Moreover, the majority of participants were assertive enough to express their negative attitudes towards the policies and legislations of the country that did not protect them completely while they were being victimised by the system.

"One of the participants who was awarded with [a] scholarship to study abroad, failed to pass HIV test and her future was tarnished".

"Their children born with the virus were being stigmatised and discriminated at school where they go to".

"At the workplace, her husband was demoted due to his status". In order to understand stigma and discrimination, one has to know the root causes that are attributed to culture, sexuality, gender, race and ethnicity, class, and how it affects PLWHA (Mahajan, Sayles, Vishal, Robert, Daniel, \& Coates, 2008). The findings further revealed the distress facing participants (HAART patients) who took part in this study.

"They said stigma and discrimination was [sic] experienced in the health care systems, where [the] majority of participants mentioned that they were being victimised by the system itself and health care workers who always shout at them whenever they felt like [it]".

"The other elderly person among the participants even pointed [out] where [the] HAART clinic was located, saying thus the reasons why these people stigmatise us because even the hospital has isolated us too".

These challenges of stigma and discrimination were expressed:

"Participates said seem as [sic] people thought they were sticking or rotten because even at church, they experienced stigma and discrimination where they were supposedly being loved, still vulnerable of being stigmatised and discriminated [against] by the community, families, and people who just look at you as if you had done something wrong".

Researchers have identified various leverages or interventions for reducing HIV / AIDS related stigma and discrimination. Most of them encourage educational interventions that aim at providing factual information about HIV / AIDS, interventions focusing on the willingness of health care providers to empower PLWHA with coping skills, mass media campaigns that are providing HIV / AIDS knowledge by targeting attitudes and behaviour, policies, and legislation targeting important structures; such as churches, the workplace, health sectors, and judicial institutions (Chirawu, 2009).

In conclusion, the study outcomes reveal that PLWHA on HAART are being stigmatised and discriminated against. It starts with the affected person, families, societies, the workplace, as well as in health care systems, government policies, and legislation that are supposedly protecting them from the ills of being stigmatised and discriminated against.

\subsection{Global implications}

Messages can be misunderstood or interpreted wrongly if they are not communicated successfully. Communication aims at trying to 
convey information meaningfully amongst people. In order to communicate properly and accurately with the purpose of understanding and being understood, one has to communicate effectively. Effective communication is important because it affects our decision-making and respect, care flourishes, trust is built, and it creates an enabling environment.

According to Clark (2008), many problems that occur in treatment protocols for a vast amount of diseases are the direct result of people failing to communicate information properly. In most cases, the communication process in the health sector involves at least two individuals. If not done properly, it might lead to misunderstanding and confusion for both parties that cause substantial risks. Kruijver, Kerkstra, Franke, Beusing and Wiel (2009) emphasise the importance of communicating information accurately. Unless patients are given relevant and sufficient health information that suits their health needs, it is very unlikely that they would participate. In other words, communicating health information improves patients' understanding of their diagnosis of a disease, facilitates learning about available services, and encourages them to participate in decisions making about their own health. The communication process, however, depends on patients' educational level, cultural background, and their immediate needs (Kruijver, et al., 2009).

Communicating health information to people living with HIV / AIDS on Highly Active Antiretroviral Therapy (HAART) is essential for adopting healthier lifestyles. It has been found that there is a positive correlation between information and responsible living (McGuire, 2009).

Health care workers' knowledge and communication skills are essential in effective communicating with people living with HIV / AIDS on HAART; especially when the country is facing challenges in respect of fighting the spread of HIV / AIDS. Namibia is one of five SADC countries that share the same burden with other countries worldwide in containing HIV / AIDS. Currently, the number of people living with HIV are more than 180000 and 93\% are on Antiretroviral Therapy (ARVs) with a prevalence rate of $17.8 \%$, and HIV incidences amount to 39 new cases daily, $75 \%$ hospitalisations, and $50 \%$ deaths due to AIDS-related illness (UNAIDS Report on the Global AIDS epidemic, 2010). What is even more troublesome is that new HIV infections continue to outpace those patients who are added to antiretroviral treatment. More than 330000 infants and children were newly infected with HIV in 2011, and a total of 2.5 million new infections occurred in that same year. This rate has been relatively constant since 2006 . However, it was imperative for people living with HIV / AIDS (PLWHA) on HAART to understand their illness and to become accustomed to a new lifestyle (UNAIDS on the Global AIDS epidemic, 2010). In the light of the abovementioned challenges, it is important that effective communication between health professionals and patients is adhered to. Consequently, communication can be misunderstood or interpreted wrongly.

\section{Conclusions}

This paper presents the description of the perceptions of health care workers and people living HIV/AIDS on HAART achieved through main themes and sub-themes of the findings of the study. Research designs and methodologies were applied that included data analysis and reviewed literature. The paper draws attention to and concluded that health care workers have neither knowledge, nor the interpersonal communication and counselling skills to facilitate communication with PLWHA on HAART, affecting their self-efficiency with regard to managing HIV / AIDS activities; absence of communication skills guidelines; inadequate audience targeted IEC material, counselling curriculum, and manuals; training; and poor supervision from their supervisors. Consequentially, it is compromising the quality of life for PLWHA by depriving them of necessary knowledge that is accurate, timely, and relevant to their health needs. HAART patients, furthermore, request health information with regard to HIV prevention, adherence to HIV treatment, blood results feedback, sexual health, alcohol abuse, nutrition, disclosure, as well as stigmatisation and discrimination.

\section{References}

[1] Adler, R. B., Procter II, R., F., \& Towne, N., (2011). Looking out looking in. Belmont, CA: Thompson Wadsworth.

[2] Akinsegum Akinbami, A. (2012). CD4 Count Pattern and Demographic Distribution of Treatment-Naïve HIV Patients: Hematology and Blood Transfusions. Lagos, Nigeria: College of Medicine.

[3] Ashely, A. \& Lush, D. (2007). HIV and AIDS Treatment Survey. Ibis Namibia-Lironga Eparu - The Rainbow Project: Windhoek. Namibia.

[4] Babbie, E., Mouton, J. \& Strydom, H. (2011). The research process with reference to the research method section Social work theories and methodologies: Dubrovnik, Croatia: North West University, Potchefstroom, South Africa Herman.

[5] Baltazary G., Akarro R.-R., \& Mussa A.-S. (2011). some factors associated with non-adherence to antiretroviral therapy (ART) in people living with HIV/AIDS (PLHA). University of Dar es Salaam: Dar es Salaam, Tanzania: Department of Statistics.

[6] Bell, E., Mtembu, P., \& O’Sullivan, S., (2007). Sexual and Reproductive health services and HIV Testing. Perspectives and experiences of women and men living with HIV and AIDS: Reproductive Health Matters. http://dx.doi.org/10.1016/S0968-8080(07)29029-9.

[7] Bradley, M.-V., Remien, R.-H., \& Dolezal, C., (2008). Depression symptoms and sexual HIV risk behavior among serodiscordant couples. Psyhosomatic Medicine: Epub.

[8] Clark, A. (2008). Dental hygienist: Beliefs, norms, attitude and intentions towards treating HIV/AIDS patients. Florida, USA: University of South Florida.

[9] Center for Disease Control \& Prevention. (2012). National Center for HIV/AIDS. Viral Hepatitis, STD and TB Prevention. Division of STD Prevention. Centers for Disease Control and Prevention 1600 Clifton Road: Atlan.

[10]Chmielecki, A. (2008). WHAT IS INFORMATION: An Ontological Approach? Gdynia, Pomeranian District. Poland: Poland Banking.

[11]Chinn, P.-L., \& Kramer, M.-K., (2011). Integrated Theory and knowledge Development in Nursing. St. Louis Mo: Mosby.

[12]Chipare, M.-A. (2012). Conceptual framework model. University of Namibia (UNAM). Windhoek: Namibia.

[13]Chirawu, S. (2009). HIV/AIDS related Stigma and Discrimination: HIV/AIDS External Studies. Windhoek, Namibia: UNAM.

[14]Coiera, E., (2013). Expanding Knowledge: Information and Computing Sciences, Expanding Knowledge in the Medical and Health Sciences, Information and Communication Services. New York: Oxford University Press.

[15]Degu, G., Yimer, G., Berhane, Y., \& Melkamu, Y., (2006). Reproductive health needs of PLWHA on ART. Department of Community health. Medical Faculty. Ethiopia: Addis Ababa University.

[16]Deribe, K. Woldemichael, K., Wondafrash, M., Haile, A., \& Alemayehu, A., (2008). Disclosure experience and associated factors among HIV positive men and women clinical service users in southwest Ethiopia. Fayyaa Integrated Development Association-NCMI, PEPFAR-New Partners Initiative. Addis Ababa, Ethiopia: Jimma.

[17]De Vos, K. (2009). Sheffield Institute for Translational Neuroscience (SITraN): Department of Neuroscience. London, United Kingdom: The University of Sheffield.

[18] Dey, I. (2012). Qualitative data analysis: a user friendly guide for social scientists. Routledge. London.

[19]Dickoff, J., James, P., \& Wiedenbach, E., (1968). Theory and practice discipline. Part Practice orientated theory: Nursing Research. http://dx.doi.org/10.1097/00006199-196811000-00014.

[20]Edewor, N., (2010). Access to Health Information by People Living with HIV/AIDS in Nigeria: The Don L. Love Memorial Library Philosophy and Practice. Lagos, Nigeria: University Libraries:

[21]Gruskin, S., Ferguson, L., \& O’Malley, J., (2007). Ensuring sexual and reproductive health for People Living with HIV. An Overview of key human rights, Policy and Health Systems Issues. Program on International Health and Human Rights. Boston MA, USA: Harvard School of Public Health.

[22]Habtemariam, T., Tameru, B., Nganwa, D., Beyene., G., Ayanwale, L. Robnett, V., \& Wilson, W., (2008). Epidemiologic Modelling of HIV/AIDS. Use of Computational Models to Study the Population Dynamics of the Disease to Assess Intervention Strategies for Decision-Making: Advances in Systems Science and Applications (ASSA).

[23] Krueger, R.-A., \& Casey, M., (2009). Focus groups. A practical guide for applied research. Thousand Oaks. CA: Sage Publications. 
[24]Kruijver, I.-P., Kerk, S.-A., Francke, A.-L., Bensing, J., \& van de Wiel, H., (2009). BMC Nursing: Providing cancer patients with adequate treatment information important for patients' health: Occupational Health Nursing Faculty and Professionals. New York, USA: University of Florida.

[25]Leech, N. - L., \& Onwuegbuzie, A., J., (2007). An array of qualitative data analysis tools. A call for qualitative data analysis triangulation: School Psychology Quarterly. http://dx.doi.org/10.1037/10453830.22.4.557.

[26] Leech, N. - L., \& Onwuegbuzie, A., J., (2007). An array of qualitative data analysis tools. A call for qualitative data analysis triangulation: School Psychology Quarterly. http://dx.doi.org/10.1037/10453830.22.4.557

[27]Lexicon Dictionary. (2013). American Psychological Association (APA) Lexicon 2013. Retrieved from http://dictionary.reference.com/browse/lexicon

[28]Mahajan, P.-A., Sayles, J.-N., Vishal, A.-P., Robert, H.-R., Daniel, O., \& Coates, T.-J. (2008). Stigma in the HIV/AIDS epidemic. A review of the literature and recommendations for the way forward: NHI Public Access.

[29]Mah, T.- L., \& Maughan-Brown, B., (2009). Social and cultural contexts of concurrency in Khayelitsha. Working Paper. Cape Town, South Africa. Centre for Social Science Research.

[30]Malmberg, E.- D., Harmon, G., Nauer, T., \& Richard, F., (2012). Improving HIV/AIDS Knowledge Management Using EHRs. Schoo of Information, The University of Texas at Austin, Austin: PMCID.

[31]McGuire, M. (2009). The New Professionalism and Collaborative Activity in Local Emergency Management: In the Collaborative Public Manager. Washington, DC: Georgetown University Press.

[32]Meliones, J.-N., Alton, M., Mericle, J., Ballard, R., Cesari, J., Frush, K.-S., \& Mistry, K., (2008). Communication leadership. USA: Oakbrook Terrace, IL: The Joint Commission

[33] Melville, S., \&Goddard, W. (2012). Research Methodology. An Introduction. 2nd Edition. Lansdowne: Juta \& Co, Ltd.

[34]Ministry of Health and Social Services. (2008). National HIV Sentinel Survey. Directorate of Special Programs Response Monitoring and Evaluation Sub-division. Windhoek, Namibia: MoHSS.

[35] Ministry of Health and Social Services. (2009). HIV/AIDS in Namibia. Behavioral and Contextual Factors Driving the Epidemic Measure Evaluations. Macro -International. Windhoek, Namibia: Inc. USAID.

[36]Modo, I. V., O., Modo, F., N., \& Enang, P., I., (2011). Socio-cultural Factors Responsible for Increasing Rate of HIV/AIDS in Akwa Ibom State of Nigeria. Department of Sociology and Anthropology. Department of Educational Foundation. Guidance and Counselling: University of Uyo. Nigeria: Akwa Ibom State.

[37]Ngozi, C., Mbonu, B., \& Nanne, K., De Vries, K., (2009). Stigma of People with HIV/AIDS in Sub-Saharan Africa. A Literature Review. Department of Health Promotion. School of Public Health and Primary Care. Faculty of Health, Medicine and Life Sciences, Maastricht University. Maastricht, Netherlands: CAPHRI.

[38] Onwuegbuzie, A. J. (2009). A Qualitative Framework for Collecting and Analyzing Data in Focus Group Research: Department of Educational Leadership and Counselling. Sam Houston State: University Huntsville.

[39] Oxford dictionary. (2013). Department of the University of Oxford: Panorama. Oxford Regional Business in Southern Africa. Good wood Cape Town, South Africa: ORBIS Oxford University Press.

[40]Pecora, P. J., Cherin, D., Bruce, E., \& de Jesus Arguello, T., (2010). Strategic supervision. A brief guide for managing social service or ganizations. Thousand Oaks, CA: SAGE.

[41]Rehm, D. (2012). Diagnosing and Treating Lyme Disease: The WAMU NPR member-station in Washington. D.C., USA: WAMU.

[42]Robinson, L., Segal, J., \& Segal, R., (2011). Effective communication. Improving communication skills in business and relationships. Qualitative data analysis: a user friendly guide for social scientists London Routledge.

[43] Shenton, A. K. (2012). Strategies for ensuring trustworthiness: Qualitative research projects Division of Information and Communication Studies. School of Informatics Northumbria University, Newcastle upon Tyne: Lippitonman Building.

[44]UNAIDS Global AIDS Epidemic Update. (2009). AIDS epidemic update. World Health Organization Library Cataloguing. Publication Data. Switzerland, Geneva: UNAIDS Publication.

[45]UNAIDS. (2010). Report on the Global AIDS epidemic 2010: UNAIDS 10.11/JC 1958E. WHO Library cataloguing. Geneva, Switzerland: UNAIDS

[46]UNAIDS Global AIDS Epidemic Update. (2009). AIDS epidemic update. World Health Organization Library Cataloguing. Publication Data. Switzerland, Geneva: UNAIDS Publication.
[47]UNAIDS Global AIDS Response Progress Reporting. (2012). Monitoring the 2011 Political Declaration on HIV/AIDS. Directorate of Special Programmes. Division Expanded National HIV/AIDS Coordination Subdivision. Response Monitoring and Evaluation: UNAIDS.

[48]Webster, M., (2012). Medical online Dictionary. An Encyclopedia Britannaca Company. Retrieved from www.merriam-webster.com

[49]Wily, J. (2011). Mechanism of HIV antiretroviral drugs progress toward drug resistance. Innovation Center for Research and Development of Medical Diagnostic Technology Project. Department of Transfusion Medicine. Faculty of Allied Health Sciences. Chulalongkorn University: Bangkok 10330. Thailand.

[50] World Health Organization. (2009). towards universal access. Scaling up priority HIV/AIDS interventions in the health sector. Progress report, 30 September 2009. Paris. Geneva. Switzerland: World Health Organization Press.)

[51]Wouda, J.-C., Van de Wiel, H., B., M., (2012). The communication competency of medical students, residents, and consultants: Patient Education and Counselling. http://dx.doi.org/10.1016/j.pec.2011.03.011. 